\title{
Mechanical behaviour of Portland cement mortars with incorporation of Al-containing salt slags
}

\author{
D.A. Pereira ${ }^{\mathrm{a}}$, Barroso de Aguiar $^{\mathrm{b}}$, F. Castro ${ }^{\mathrm{c}}$, M.F. Almeida ${ }^{\mathrm{d}}$, J.A. Labrincha ${ }^{\mathrm{e}}{ }^{*}$ \\ ${ }^{a}$ Dep. Eng. Mecânica, Instituto Superior de Engenharia, 4200 Porto, Portugal \\ ${ }^{\mathrm{b}}$ Dep. Eng. Civil, Universidade do Minho, 4810 Guimarães, Portugal \\ ${ }^{\mathrm{c}}$ Dep. Eng. Mecânica, Universidade do Minho, 4810 Guimarães, Portugal \\ ${ }^{\mathrm{d}}$ Dep. Eng. Metalúrgica, Universidade do Porto, LEPAE, 4000 Porto, Portugal \\ ${ }^{\mathrm{e}}$ Dep. Eng. Cerâmica e do Vidro, Universidade de Aveiro, UIMC, 3810-193 Aveiro, Portugal
}

Received 19 November 1999; accepted 28 March 2000

\begin{abstract}
Recovery of a salt cake slag produced from aluminum scrap re-melted in rotary furnaces, at the lowest cost, while complying with all environmental laws is the main objective of this study. The characterisation of the slag residue involved determinations of the water leaching conditions, toxicological analysis, chemical analysis of the leaching waste, and mineralogical composition. A two-phase study was made to determine the effect of waste additions on mechanical properties of cement mortars, involving partial replacements of either sand or cement. SEM characterisation of fracture surfaces was also made. Partial substitution of cement, which is the most expensive component of the mortar, by salt slag has both environmental and economical advantages. However, only small amounts (up to $10 \mathrm{wt}$ \%) can be replaced by washed slag without significant damage to mortar characteristics. Sand substitution by slag is less problematic and 30-50 wt.\% replacement levels are easily achieved. However, the direct economical impact is less relevant. The incorporation of unwashed slag in impracticable, as a result of noxious gases released and significant volumetric expansion effects. (C) 2000 Elsevier Science Ltd. All rights reserved.
\end{abstract}

Keywords: Waste management; Mortar; Portland cement; Salt slag; Mechanical properties

\section{Introduction}

During the recovery of aluminum through scrap recycling, a great quantity of oxide layer forms on the surface of molten metal, which has to be removed from the melt to refine the quality of the final product. In order to promote an easier separation and to avoid the formation of additional oxidation phases, it is common to use a protective salt cover. The molten salt flux promotes the coalescence of suspended metal droplets and helps separate the clean metal from oxide contamination. The scum formed on the surface of molten metal is made of a mixture of oxides, fluxes, gases, and some free metal. Its common name is aluminum salt slag.

\footnotetext{
* Corresponding author. Tel.: +351-234-370250; fax: +351-234425300 .

E-mail address: jal@cv.ua.pt (J.A. Labrincha).
}

Fluxing techniques and production practices strongly change throughout different industries giving several types of dross, normally called white and black. White dross is produced from a melting process of strongly pure scraps, having high aluminum metal content. In this case, fluxing inside the furnace is practically absent and the color of dross skimmed is gray or metallic white. Black dross is produced by secondary aluminum smelters, by using rotary furnaces to melt old casting and a low-grade aluminum scrap. Fluxes are composed of mixtures of sodium and potassium chlorides, and contain small amounts of fluorides. At high molten-metal temperatures, the flux melts and becomes dark. This slag is highly salt-rich $(50-70 \%)$ and is the object of our study.

The Environmental Protection Agency of the US (EPA) classifies these residues as toxic and hazardous wastes [1]. Even the poorer aluminum-rich residue is very prone to leaching chlorides when in contact with rainfall or groundwater. Moreover, salt slag evolves gases when in contact with water, namely hydrogen, ammonia, methane, and 
small amounts of hydrogen sulfide and phosphine. Some of these gases are explosive, poisonous, and might produce extremely unpleasant odors [2]. The correct disposal of these wastes causes environmental concerns. The treatment of salt cake to minimize land-filling problems is generally done in Europe, US and Canada. Typically, a dry separation process of the aluminum, followed by leaching and filtration steps to separate the soluble flux salts from the insoluble oxides, and crystallization to regenerate the salt fluxes in usable form are the main steps of that treatment. Thus, the waste material is separated into a suitable melted metallic fraction, a reusable salt flux and an inert oxide mainly composed of $\mathrm{Al}_{2} \mathrm{O}_{3}$ and a spinel which has several possible industrial applications including the construction sector, to improve the mechanical strength of mortar and concrete.

\section{Experimental}

\subsection{Characterisation of the residue}

A salt slag from a Portuguese aluminum-alloy producing industry (Alpor, Braga) was used in this work. The adaptability of the residue to the washing by water process was studied first by doing leaching tests in several conditions and by measuring the compositions of the insoluble part and of the solution [3]. The correct sampling of the slag was obtained by following normalised methods
[4]. Grain size distribution of the washed residue was made by sieving and the following result was obtained: $>1.40 \mathrm{~mm}=11 \% ; 0.5-1.40 \mathrm{~mm}=7 \% ; 0.18-0.50 \mathrm{~mm}=$ $19 \% ;<0.18 \mathrm{~mm}=60 \%$. Chemical composition of each sieved fraction was estimated by X-ray fluorescence (see Table 1). Mineralogical determinations were also obtained by X-ray diffraction.

\subsection{Incorporation in cement mortars}

These tests are contained in a more embracing study about the economical viability of the development of a correct technology for treatment of salt slag containing insoluble aluminum oxides. In this case, the search for an alternative way to obtain an alumina-rich product that could be economically interesting to be incorporated in construction materials, like in cement mortars, is the central goal of the work.

Mortar preparation was conducted according to the EN196-1 procedure [5]. Two sets of experiments were done, one involving the substitution of sand by the residue and another where cement by slag substitution was promoted. Flexural and compression strengths were measured on prismatic samples, having dimensions of $40 \times 40 \times 160$ $\mathrm{mm}$. These measurements were carried out after curing periods of 3, 7, 28, and 90 days in a standard testing machine (Autograph AG-A, Shimadzu, Japan). According to standard procedures [5], the arithmetic mean of six tests was determined.

Table 1

Chemical analysis (XRF) of different sieved fractions of the washed residue (\% or ppm)

\begin{tabular}{|c|c|c|c|c|c|c|c|c|c|c|}
\hline \multirow[b]{2}{*}{ Component } & \multicolumn{10}{|c|}{ Retained fractions by sieving (mm) } \\
\hline & 1.00 & 0.71 & 0.50 & 0.355 & 0.25 & 0.18 & 0.125 & 0.09 & 0.063 & $<0.063$ \\
\hline $\mathrm{NaCl}$ & 0.9 & 0.8 & 0.7 & 0.8 & 0.6 & 0.5 & 0.3 & 0.4 & 0.3 & 0.3 \\
\hline $\mathrm{KCl}$ & 2.0 & 2.3 & 1.8 & 1.9 & 1.4 & 0.9 & 0.7 & 0.5 & 0.5 & 0.6 \\
\hline $\mathrm{MgO}$ & 9.7 & 9.6 & 10.0 & 9.9 & 10.1 & 10.2 & 10.2 & 10.4 & 10.4 & 10.0 \\
\hline $\mathrm{Al}_{2} \mathrm{O}_{3}$ & 60.6 & 62.4 & 62.2 & 61.4 & 60.4 & 61.8 & 65.3 & 70.9 & 69.7 & 69.6 \\
\hline $\mathrm{SiO}_{2}$ & 8.4 & 6.6 & 6.5 & 5.7 & 5.8 & 4.3 & 4.1 & 4.3 & 4.3 & 4.4 \\
\hline $\mathrm{P}_{2} \mathrm{O}_{5}$ & 0.33 & 0.40 & 0.35 & 0.40 & 0.36 & 0.40 & 0.34 & 0.34 & 0.34 & 0.32 \\
\hline $\mathrm{S}^{*}$ & 1980 & 2070 & 1780 & 1960 & 1730 & 1780 & 1470 & 1820 & 1830 & 1610 \\
\hline $\mathrm{CaO}$ & 7.1 & 7.3 & 7.1 & 7.0 & 6.6 & 5.8 & 6.3 & 5.1 & 5.7 & 6.0 \\
\hline $\mathrm{TiO}_{2}$ & 4.9 & 6.4 & 6.6 & 8.4 & 10.4 & 12.1 & 9.2 & 4.7 & 5.2 & 5.1 \\
\hline $\mathrm{V}_{2} \mathrm{O}_{5} *$ & 290 & 390 & 470 & 370 & 430 & 440 & 400 & 240 & 290 & 330 \\
\hline $\mathrm{Cr}_{2} \mathrm{O}_{3} *$ & 1590 & 1220 & 1790 & 2370 & 2150 & 1500 & 1410 & 1240 & 1310 & 1180 \\
\hline $\mathrm{MnO}^{*}$ & 1570 & 1360 & 1430 & 1250 & 1300 & 1110 & 910 & 890 & 900 & 960 \\
\hline $\mathrm{Fe}_{2} \mathrm{O}_{3}$ & 2.6 & 2.8 & 3.0 & 2.7 & 2.6 & 2.2 & 2.0 & 1.9 & 1.9 & 2.0 \\
\hline $\mathrm{Ni}^{*}$ & 170 & 170 & 190 & 250 & 150 & 130 & 190 & 210 & 170 & 240 \\
\hline $\mathrm{Cu}^{*}$ & 23,800 & 8100 & 9500 & 8300 & 8300 & 6300 & 5700 & 4700 & 5100 & 6000 \\
\hline $\mathrm{Zn} *$ & 1270 & 1480 & 1300 & 960 & 910 & 690 & 550 & 490 & 540 & 590 \\
\hline $\mathrm{Sr}^{*}$ & 150 & 160 & 160 & 170 & 160 & 130 & 110 & 90 & 100 & 100 \\
\hline $\mathrm{ZrO}_{2} *$ & 460 & 240 & 640 & 690 & 450 & 460 & 490 & 300 & 330 & 370 \\
\hline $\mathrm{Sn}^{*}$ & 270 & 350 & 220 & 170 & 150 & 170 & 160 & 150 & 150 & 170 \\
\hline $\mathrm{BaO}^{*}$ & 860 & 1050 & 1170 & 1470 & 1670 & 1720 & 1980 & 1680 & 1860 & 1810 \\
\hline $\mathrm{PbO}^{*}$ & 1730 & 2210 & 2030 & 2190 & 2170 & 2290 & 2190 & 2080 & 2070 & 2150 \\
\hline Other* & 157 & 142 & 190 & 233 & 99 & 304 & 234 & 200 & 176 & 121 \\
\hline
\end{tabular}

* Results in parts per million (ppm). 
The composition of non-slag-containing mortars was also normalised [6] and were obtained by mixing $1350 \mathrm{~g}$ of standard sand (silica-rich) with $450 \mathrm{~g}$ of cement (Portland type I, class 42.5) and $225 \mathrm{ml}$ of water. Several mixtures containing different weight percentages of previously washed residue were prepared (see Table 2). The high water demand of the slag led to the preparation of mixtures that contain relatively higher amount of water to get enough workability. Different tests involving coarse (up to $2 \mathrm{~mm}$ ) and fine particle fractions $(<180 \mu \mathrm{m})$ were made.

The curing process was also conducted in normalised conditions with mortar samples immersed in water and placed inside a humidity-controlled chamber.

\section{Discussion of results}

As an attempt to define optimal washing conditions, the following laboratory-scale sequence was tested: (i) a sample of milled and dry salt slag was stirred for $1 \mathrm{~h}$ in a glass beaker with deionised water corresponding to the solid/ liquid ratio of 1:2; (ii) a clear liquid sample was extracted and its density and amount of dissolved salts were determined by pycnometry and evaporation methods, respectively; (iii) these salts were redissolved into deionised water that was added to the slag sample in the beaker to keep constant the solid/liquid ratio (1:3); (iv) steps (ii) and (iii) were repeated for 1:4, 1:5, 1:6, 1:7, and 1:8 solid/liquid ratios. Fig. 1 shows the density evolution of the liquid in contact with salt slag as well as the percentage of salt slag dissolved. Once the 1:5 washing step was reached, almost no more salt slag was dissolved.

To achieve optimal levels of washing efficiency when using cold water, another sequential test was done, starting from a suspension made by the solid/liquid ratio of 1:4. The salt slag was then added to reach final ratios of $3: 4$ and both liquid density and amount of dissolved salt were determined (Fig. 2).

Leaching treatment was conducted by dissolving $50-$ $60 \%$ of the as-received material, which proved to be very effective in the removal of alkaline salts (almost complete). Leached waste is very dark and is mainly

Table 2

Compositions of tested mortars involving slag fractions under $180 \mu \mathrm{m}$

\begin{tabular}{lcllrl}
\hline \multirow{2}{*}{$\begin{array}{l}\text { Type of } \\
\text { substitution }\end{array}$} & $\begin{array}{l}\text { Percentage } \\
\text { slag }\end{array}$ & \multicolumn{5}{l}{ Amount of components (g) } \\
\cline { 3 - 6 } & Sand & Cement & Slag & Water \\
\hline Sand/slag & 0 & 1350 & 450 & 0 & 225 \\
& 10 & 1305 & 450 & 45 & 225 \\
& 20 & 1260 & 450 & 90 & 230 \\
& 30 & 1215 & 450 & 135 & 250 \\
Cement/slag & 10 & 1350 & 405 & 45 & 225 \\
& 30 & 1350 & 315 & 135 & 225 \\
& 50 & 1350 & 225 & 225 & 250 \\
& 70 & 1350 & 135 & 315 & 260 \\
\hline
\end{tabular}

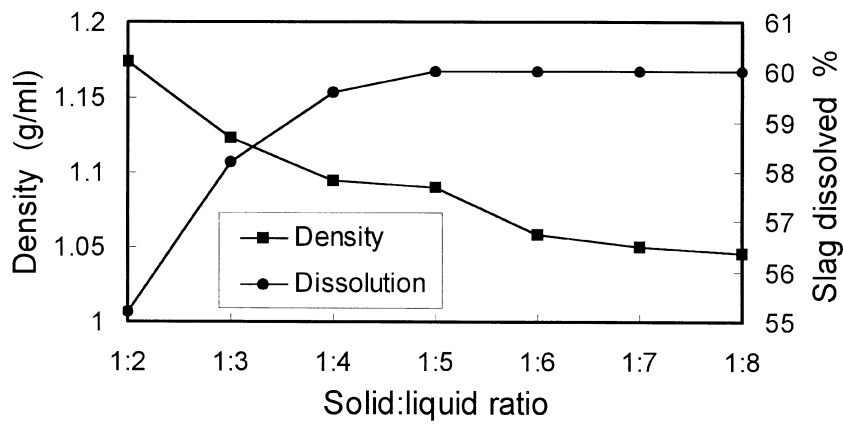

Fig. 1. Dissolution of salt slag having different densities as a function of the water added.

composed of aluminum oxides, hydroxides and silicates, and residual chlorides. Saturated brine contains about $300 \mathrm{~g} / 1$ of sodium/potassium chlorides and its density is about 1.2. Leaching tests of washed slags allowed their classification as non-toxic materials, while the asreceived residues were highly toxic. The inertness character of the treated slag allows its use for different applications $[7,8]$.

Salt slag is initially composed of a heterogeneous mass in which two main mineral groups were found: (i) watersoluble compounds, mainly alkaline salts $(\mathrm{NaCl}$ and $\mathrm{KCl})$ but also traces of $\mathrm{AlN}, \mathrm{AlC}_{3}$ and $\mathrm{Al}_{2} \mathrm{~S}_{3}$; (ii) non-soluble compounds in water, mainly corundum $\left(\alpha-\mathrm{Al}_{2} \mathrm{O}_{3}\right), \mathrm{Al}_{2} \mathrm{~S}$, a spinel of the system $\mathrm{MgO}-\mathrm{Al}_{2} \mathrm{O}_{3}$, quartz, and $\beta$ $\mathrm{CaO} \cdot \mathrm{SiO}_{2}$. The main crystalline phases present in the fine fraction are given in Fig. 3. TGA analysis showed that the material is non-reactive above nearly $600^{\circ} \mathrm{C}$, while under this temperature, strong decomposition reactions are observed due to the presence of hydroxides and organic matter.

It was found impossible to make cement mortars containing non-washed slags due to the volumetric expansion observed during setting. The chloride content is significant and high concentrations of noxious gases are released.

The dependence of the mechanical resistance of samples as a function of slag amount, the setting time and the average grain size of the residue is shown in Figs. 4-6

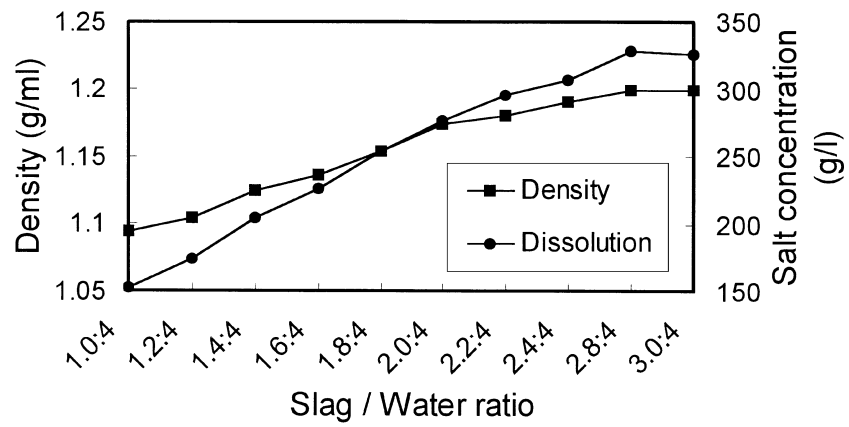

Fig. 2. Characteristics of the washing solution of the salt slag. 


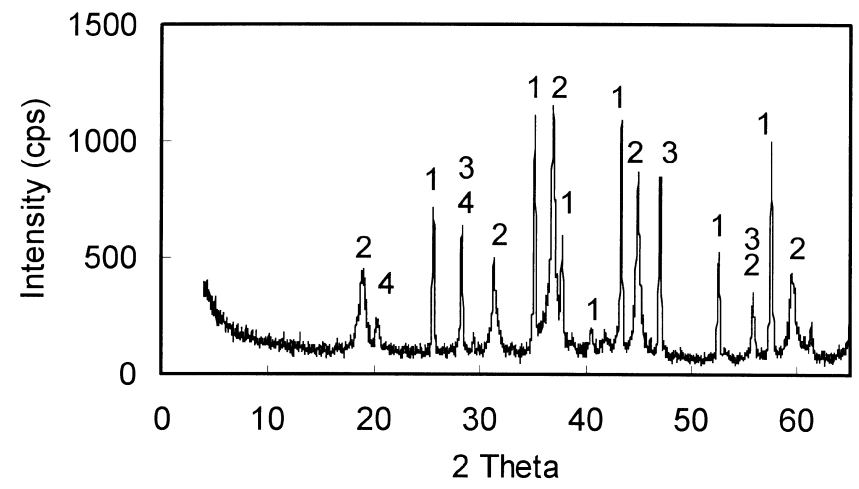

Fig. 3. XRD pattern of the powder fraction under $180 \mu \mathrm{m}$. (1) $\alpha-\mathrm{Al}_{2} \mathrm{O}_{3}$, (2) $\mathrm{MgAl}_{2} \mathrm{O}_{4}$, (3) $\mathrm{CaF}_{2}$, (4) $\mathrm{Al}_{2} \mathrm{Si}_{4} \mathrm{O}_{10}$. for samples in which residue for sand substitution was promoted. The addition of coarse slag grains promotes deleterious effects on the mechanical properties of the mortars. Samples containing $20 \%$ and $30 \%$ of slag seem to be weaker than the others (Fig. 4), but the differences tend to decrease for longer curing periods. After 28 days, the resistance of all samples tends to be more similar. This observation is an indication of the retarding action of the sludge, probably due to its acidic nature and incomplete correction of $\mathrm{pH}$.

On the contrary, the addition of small amounts (up to $30 \mathrm{wt} . \%$ ) of washed fine-grained slag did not decrease the mechanical properties of the mortars (Fig. 5). The good dispersion of these smaller particles through the cement matrix might assure the formation of a suitable microstructure. Therefore, the slag cannot be considered as a

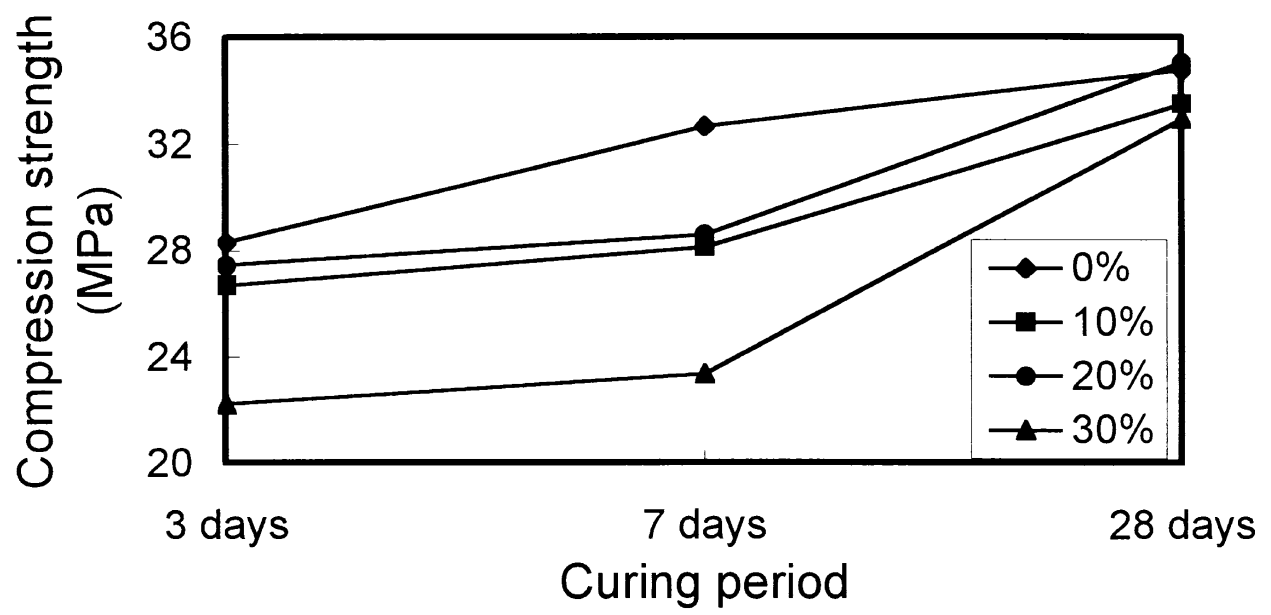

(a)

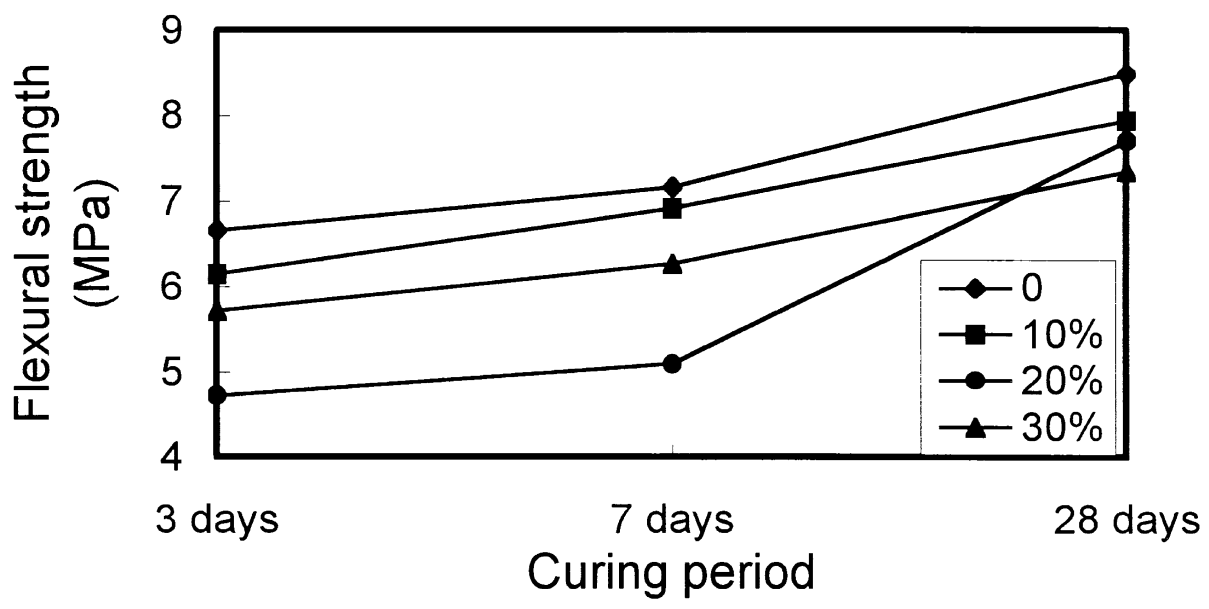

(b)

Fig. 4. Dependence of the mechanical resistance of mortars on the curing period and on added amount of washed coarse salt slag $(<2 \mathrm{~mm})$ to partially substitute the sand fraction: (a) compression and (b) flexural strengths. 


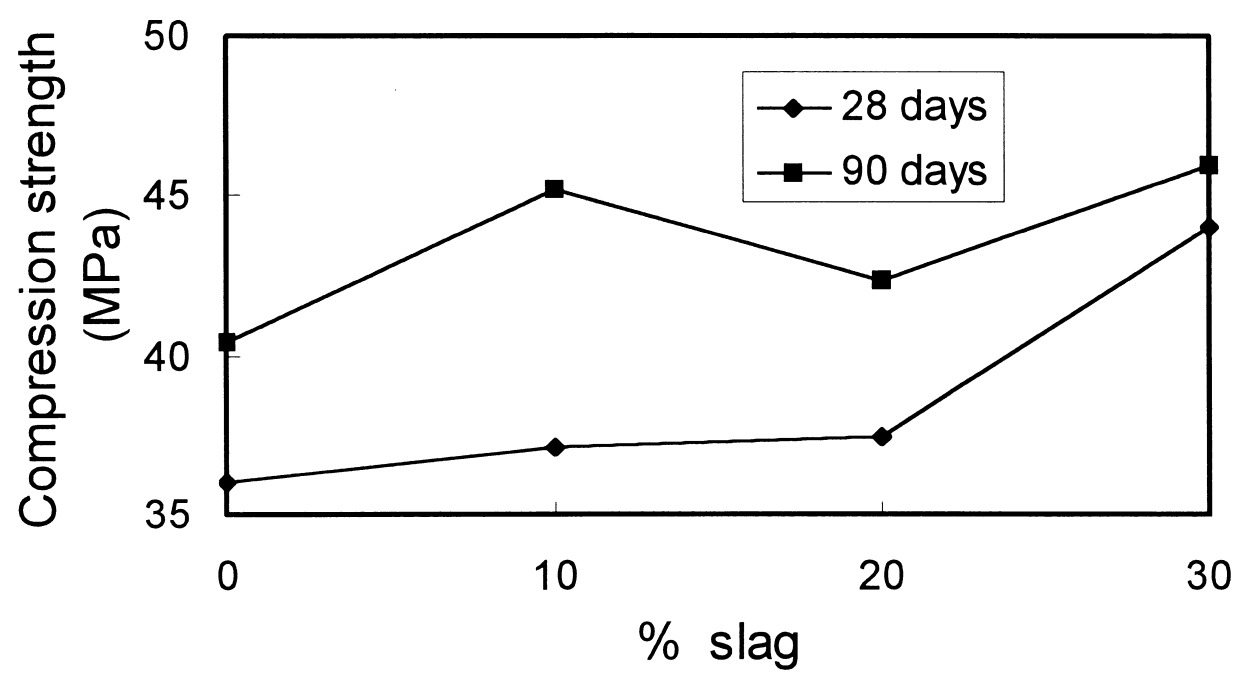

(a)

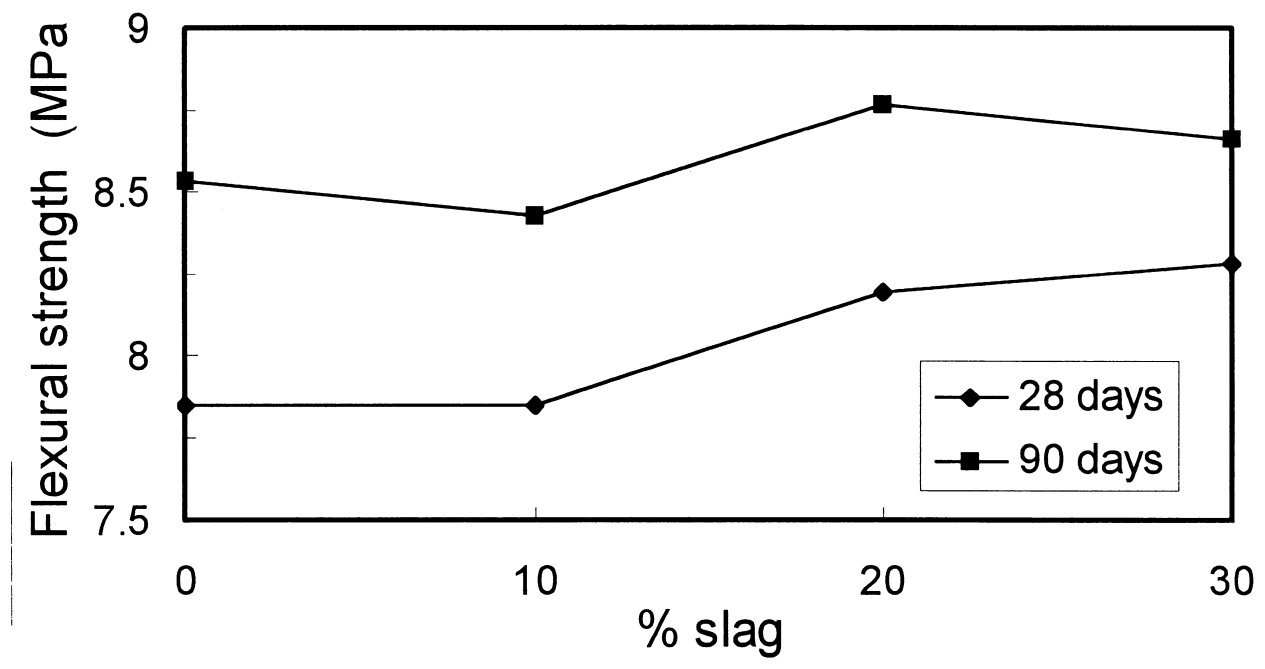

(b)

Fig. 5. Dependence of the mechanical resistance of mortars on the curing period and on the added amount of washed fine salt slag $(<180 \mu \mathrm{m})$ to partially substitute the sand fraction: (a) compression and (b) flexural strengths.

totally inactive additive. Moreover, the previous slag washing treatment is certainly more efficient by using finer particles and ageing effects on the materials properties are less probable.

A direct comparison of samples containing coarse- and fine-grain residue additions is given in Fig. 6. The benefit is much more evident on using fine-grained slag fractions, especially on flexural resistance of the mortars. However, the sieving operation enhances the treatment cost of the residue, as it requires a previous (and efficient) drying step and the use of grinding facilities to recover the coarser particles.

The typical microstructures (SEM) of fracture surfaces of mortars with or without slag incorporation (partially replacing the sand) are shown in Fig. 7. The changes are less visible, but slag-containing samples seem to be more compact, which is in accordance with improving mechanical characteristics previously discussed. 


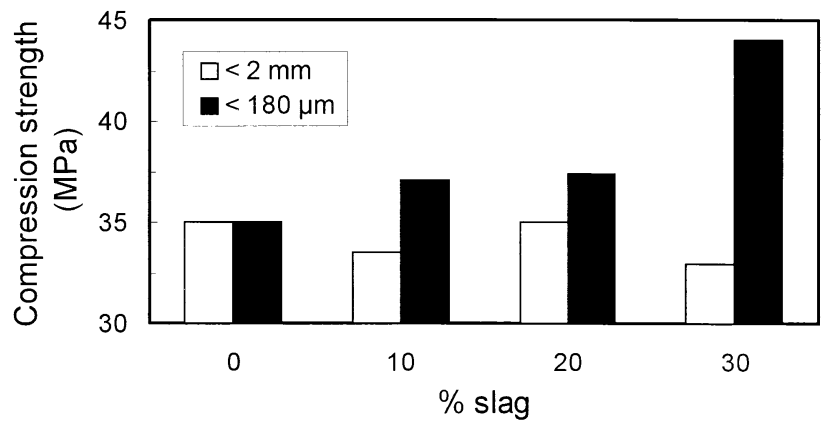

(a)

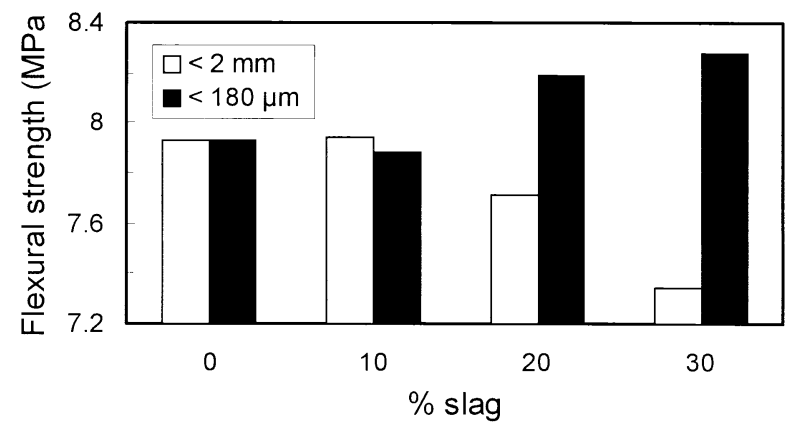

(b)

Fig. 6. Changes in the mechanical resistance of mortars after curing for 28 days as a function of the amount and average grain size of washed salt slag used to partially replace the sand: (a) compression and (b) flexural strengths.

Fig. 8 shows the mechanical behaviour of samples where cement for slag substitutions were promoted. Both compression and flexural strengths decrease with increasing slag contents, irrespective of the curing period. This deleterious trend was predicted and would also be expected for any kind of cement for inert substitution, whatever the nature of the inert material. In fact, the structural support of these mortars is obviously given by the cement, and its decreasing amount has a negative impact on the mechanical resistance.

The maximum chloride contents for different concrete types are given in Table 3 [9]. The 30\% slag-containing mortars, corresponding to the higher and acceptable incorporation limit, were tested and chloride contents (expressed as percentage of the cement) of about $0.4 \%$ were determined. This confirms the potential of this incorporation route for non-hazardous slag on mortar fabrication for normal concrete.

\section{Conclusions}

The incorporation of washed aluminum-containing salt slag in cement mortars seems possible within controlled limits. For samples containing a fixed amount of cement, the slag for sand substitution (for levels up to $30 \mathrm{wt} . \%$ ) did not promote deleterious effects on the mechanical properties. At the same time, some properties benefit was found for samples containing fine slag particles (under $180 \mu \mathrm{m}$ ) and especially for longer curing periods (28 or 90 days). Slag for cement substitution on samples containing a fixed amount of sand strongly affects the mechanical properties, and low tolerable levels are accepted (up to 10 wt.\%). Even this result might be attractive from an economical point of view, due to the high cost of the cement. At the same time, this replacement seems to be a helpful solution to partly solve the environmental problem associated with the production of such type of slags. The incorporation of salt slag increases the mortar water demand, making this effect more pro-

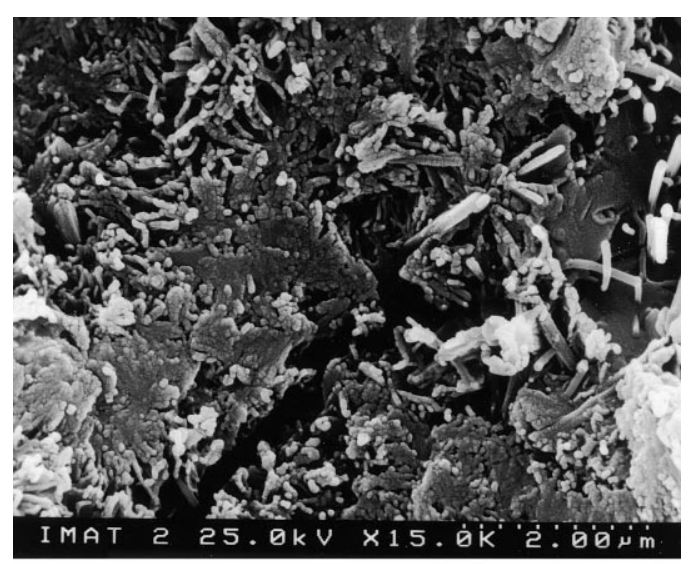

(a)

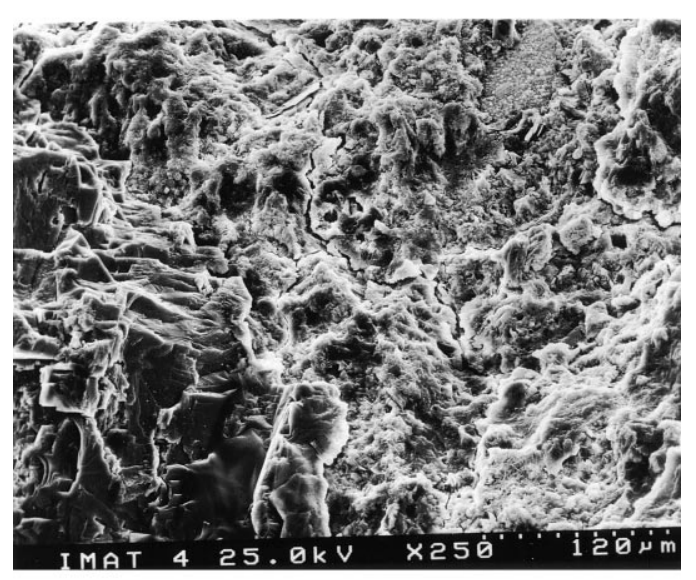

(b)

Fig. 7. Scanning electron micrographs obtained on fracture surfaces of (a) slag-free and (b) 30 wt.\% slag-containing mortars. 


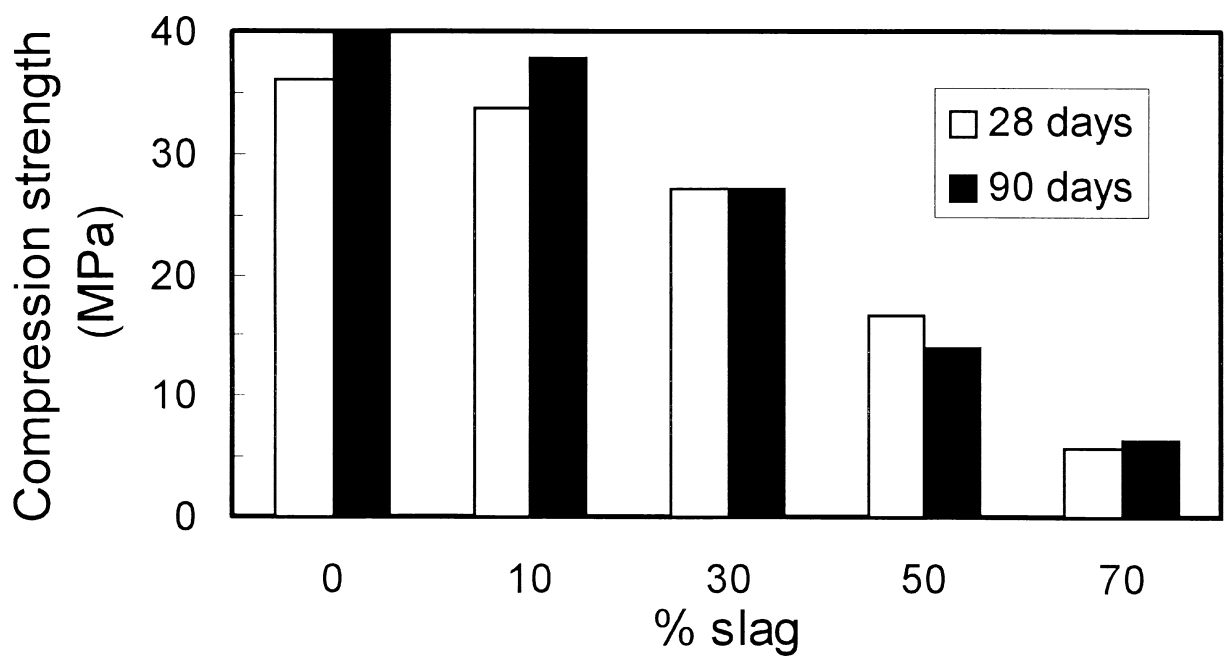

(a)

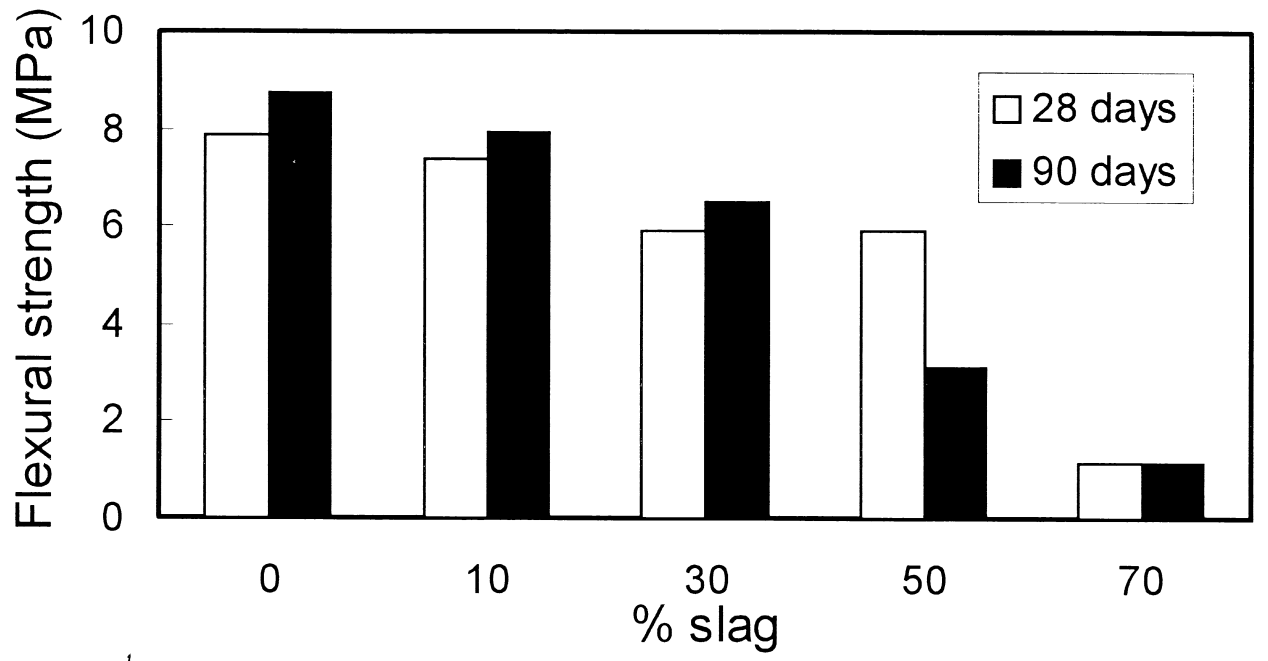

(b)

Fig. 8. Dependence of the mechanical resistance of mortars on the curing period and on the added amount of washed fine salt slag $(<180 \mu \mathrm{m})$ to partially substitute the cement: (a) compression and (b) flexural strengths.

nounced with the use of finer particles and for cement by slag replacing samples.

Table 3

Maximum limits of chloride content in different concrete types

\begin{tabular}{ll}
\hline Type of concrete & $\mathrm{Cl}$ percentage in cement \\
\hline Normal & 1 \\
Reinforced & 0.4 \\
Pre-stressed & 0.2 \\
\hline
\end{tabular}

\section{References}

[1] J.S. Viland, A secondary's view of recycling, Recycling of Metals and Engineered Materials, Minerals, Metals and Materials Society, 1990, p. 427.

[2] I. Alfaro, R. Ballhord, The applications of aluminum-oxide obtained from the recycling of aluminium, in: I. Alfaro (Ed.), Proceedings of the Third International Conference on Recycling of Metals, Barcelona, 1997, pp. 405-419.

[3] D.A. Pereira, F. Castro, F. Almeida, Characterization of Al-rich salt scories, in: L.G. Rosa (Ed.), Proceedings of 8th Congress of Portuguese Materials Society, Marinha Grande, Vol. 1, 1997, pp. 182-189. 
[4] Association Francaise de Normalisation X 32-210, Déchets, Essai de lixiviation, Décember, 1992.

[5] European Committee for Standardisation, EN 196-1, Methods of Testing cement; Determination of Strength, May, 1987.

[6] European Committee for Standardisation, ENV 197-1, Cements: Definition, Composition, Specifications and Conformity Criteria: Part 1. Usual Cements, 1992.

[7] D.M.S. Couto, J.A. Labrincha, R.F. Silva, L. Guise, F. Castro, In- corporation of hydroxide-metal containing sludges in ceramic bricks, Ceramica Acta, in press.

[8] D.M.S. Couto, J.A. Labrincha, R.F. Silva, F. Castro, Inertization of metallurgical sludges in clay-based ceramics, in: C.S. Gomes (Ed.), Proceedings 2nd International Meeting of the Mediterranean Clay Groups, Vol. 2, 1998, pp. 214-219.

[9] European Committee for Standardisation, ENV 206, Concrete-Performance, Production, Placing and Compliance Criteria, October, 1993. 